Herzschr Elektrophys 2021 · 32:353-358 https://doi.org/10.1007/s00399-021-00787-y Received: 2 March 2021 Accepted: 16 June 2021

Published online: 16 July 2021

(c) The Author(s) 2021

\section{Role of assist device implantation and heart transplantation in the long-term outcome of patients with structural heart disease after catheter ablation of ventricular tachycardia}

\author{
Angeliki Darma · Livio Bertagnolli • Borislav Dinov · Alireza Sepehri Shamloo \\ Federica Torri - Elena Efimova · Nikolaos Dagres · Daniela Husser-Bollmann . \\ Andreas Bollmann · Gerhard Hindricks · Arash Arya \\ Department of Electrophysiology, Heart Center University Leipzig, Leipzig, Germany
}

\title{
Abstract
}

Introduction: Ablation of ventricular tachycardias (VTs) in patients with structural heart disease (SHD) has been associated with advanced heart failure and poor survival. Methods and results: This matched case-control study sought to assess the difference in survival after left ventricular assist device (LVAD) implantation and/or heart transplantation (HTX) in SHD patients undergoing VT ablation. From the initial cohort of 309 SHD patients undergoing VT ablation (187 ischemic cardiomyopathy, mean age $64 \pm 12$ years, ejection fraction of $34 \pm 13 \%), 15$ patients received an LVAD and nine patients HTX after VT ablation during a follow-up period of $44 \pm 33$ months. Long-term survival after LVAD did not differ from the matched control group $(p=0.761)$, although the cause of lethal events was different. All post-HTX patients survived during follow-up.

Conclusion: In this matched case-control study on patients with SHD undergoing VT ablation, patients that received LVAD implantation had similar survival compared to the control group after 4-year follow-up, while the patients with HTX had a significantly better outcome.

Keywords

Left ventricular assist device $\cdot$ Heart failure $\cdot$ VT ablation $\cdot$ Long-term outcome · Mortality

\section{Introduction}

Recurrent, drug-refractory ventricular tachycardias (VTs) in patients with structural heart disease is a common manifestation of advanced heart failure [1]. The changes in drug therapy over the last decades, as well as the implementation of intracardiac defibrillators and cardiac resynchronisation devices have increased life expectancy. Furthermore, developments in ablation technique and 3D mapping systems made a wider selection of patients eligible for VT ablation possible [1]. Nevertheless, the ablation of complex arrythmias is becoming more challenging as the age and comorbidities of the population increase [2-4]. Even with successful ablations, the long-term outcome remains unsatisfactory due to the persistent high mortality rates within the first 5 years [2-4]. Advanced New York Heart Association (NYHA) class, low left ventricle ejection fraction (LVEF), elevated left ventricular end-diastolic volume (LVEDV), ischemic cardiomyopathy (ICM), electrical storm (ES) with recurrent shocks, advanced age as well as frequent comor- 
Table 1 Baseline characteristics, procedural data and long-term outcome for the control group and the left ventricular assist device (LVAD)/heart transplantation (HTX) group

\begin{tabular}{|c|c|c|c|c|}
\hline Variable & Total & $\begin{array}{l}\text { Control } \\
\text { group }\end{array}$ & $\begin{array}{l}\text { LVAD/HTX } \\
\text { group }\end{array}$ & $p$-Value \\
\hline \multicolumn{5}{|l|}{ Baseline characteristics } \\
\hline $\begin{array}{l}\text { Male } \\
\text { Female }\end{array}$ & $\begin{array}{l}38(91 \%) \\
4(9 \%)\end{array}$ & $\begin{array}{l}19(91 \%) \\
2(9 \%)\end{array}$ & $\begin{array}{l}19(91 \%) \\
2(9 \%)\end{array}$ & 1.000 \\
\hline Age (mean years) & $58 \pm 12$ & $60 \pm 14$ & $57 \pm 10$ & 0.414 \\
\hline $\begin{array}{l}\text { ICM } \\
\text { NICM }\end{array}$ & $\begin{array}{l}29(69 \%) \\
13(31 \%)\end{array}$ & $\begin{array}{l}16(76 \%) \\
5(24 \%)\end{array}$ & $\begin{array}{l}13(62 \%) \\
8(38 \%)\end{array}$ & 0.317 \\
\hline $\begin{array}{l}\text { NYHA I-II } \\
\text { NYHA III-IV }\end{array}$ & $\begin{array}{l}24(57 \%) \\
18(43 \%)\end{array}$ & $\begin{array}{l}12(57 \%) \\
9(43 \%)\end{array}$ & $\begin{array}{l}12(57 \%) \\
9(43 \%)\end{array}$ & 1.000 \\
\hline Arterial hypertension & $33(79 \%)$ & $16(76 \%)$ & $17(81 \%)$ & 0.707 \\
\hline Diabetes mellitus & $17(41 \%)$ & $9(43 \%)$ & $8(38 \%)$ & 0.753 \\
\hline Renal failure & $29(69 \%)$ & $15(71 \%)$ & $14(67 \%)$ & 0.739 \\
\hline LVEF (mean \%) & $30 \pm 9$ & $30 \pm 8$ & $30 \pm 9$ & 0.825 \\
\hline $\begin{array}{l}\text { LVEDV (mean } \mathrm{ml}) \\
\text { RV pressure }(\mathrm{mm} \mathrm{Hg}) \\
\text { Cardiac index }\left(\mathrm{l} / \mathrm{min} / \mathrm{m}^{2}\right)\end{array}$ & $\begin{array}{l}234 \pm 90 \\
31 \pm 12 \\
2.0 \pm 0.7\end{array}$ & $\begin{array}{l}227 \pm 85 \\
31 \pm 9 \\
2.2 \pm 0.3\end{array}$ & $\begin{array}{l}241 \pm 95 \\
30 \pm 13 \\
1.9 \pm 0.6\end{array}$ & $\begin{array}{l}0.617 \\
0.813 \\
0.407\end{array}$ \\
\hline $\mathrm{AF}$ & $22(52 \%)$ & $11(52 \%)$ & $11(52 \%)$ & 1.000 \\
\hline COPD & $11(26 \%)$ & $9(43 \%)$ & $2(9 \%)$ & 0.014 \\
\hline AAD (baseline) & $29(69 \%)$ & $14(67 \%)$ & $15(71 \%)$ & 0.739 \\
\hline AAD (follow-up) & $23(55 \%)$ & $12(57 \%)$ & $11(52 \%)$ & 0.757 \\
\hline $\begin{array}{l}\text { ICD primary } \\
\text { ICD secondary }\end{array}$ & $\begin{array}{l}32(76 \%) \\
8(19 \%)\end{array}$ & $\begin{array}{l}18(86 \%) \\
3(14 \%)\end{array}$ & $\begin{array}{l}14(67 \%) \\
5(23 \%)\end{array}$ & 0.223 \\
\hline \multicolumn{4}{|l|}{ PAINESC Score } & \multirow[t]{3}{*}{0.757} \\
\hline Low-intermediate & $19(45 \%)$ & $9(43 \%)$ & $10(46 \%)$ & \\
\hline High & $23(55 \%)$ & $12(57 \%)$ & $11(52 \%)$ & \\
\hline Electrical storm & $33(78 \%)$ & $16(76 \%)$ & $17(81 \%)$ & 0.707 \\
\hline \multicolumn{5}{|l|}{ Procedural data and outcome } \\
\hline Epicardial VT ablation & $11(26 \%)$ & $5(24 \%)$ & $6(29 \%)$ & 0.726 \\
\hline \multicolumn{4}{|l|}{$\mathrm{mmVT}$} & \multirow[t]{4}{*}{0.946} \\
\hline $1-2$ & $19(45 \%)$ & $10(48 \%)$ & $9(43 \%)$ & \\
\hline $3-5$ & $17(41 \%)$ & $8(38 \%)$ & $9(43 \%)$ & \\
\hline$>5$ & $6(14 \%)$ & $3(14 \%)$ & $3(14 \%)$ & \\
\hline Non-inducibility (endpoint) & $33(78 \%)$ & $16(76 \%)$ & $17(81 \%)$ & 0.707 \\
\hline Complication & $8(19 \%)$ & $3(14 \%)$ & $5(24 \%)$ & 0.432 \\
\hline VT recurrence (re-do ablation) & $23(55 \%)$ & $10(48 \%)$ & $13(62 \%)$ & 0.352 \\
\hline Death & $16(38 \%)$ & $7(33 \%)$ & $9(43 \%)$ & 0.525 \\
\hline \multicolumn{5}{|c|}{$\begin{array}{l}\text { ICM ischemic cardiomyopathy, NICM non-ischemic cardiomyopathy, LVEF left ventricle ejection frac- } \\
\text { tion, } L V E D V \text { left ventricle end-diastolic LV volume, NYHA New York Heart Association, } A F \text { atrial fibrilla- } \\
\text { tion, } V T \text { ventricular tachycardia, } A A D \text { antiarrhythmic drug, ICD implantable cardioverter/defibrillator, } \\
m m V T \text { monomorphic VT, COPD chronic obstructive pulmonary disease, RV right ventricle, PAINESD } \\
\text { score: risk model for acute cardial decompensation during ablation (pulmonary disease, age, ICM, } \\
\text { NYHA, LV-EF < }<5 \% \text {, VT-storm, diabetes mellitus type 2) }\end{array}$} \\
\hline
\end{tabular}

bidities such as lung disease, diabetes mellitus (DM), renal dysfunction and atrial fibrillation (AF) are all associated with poor prognosis [5-8].

The ongoing lack of available organs in recent decades has established the mechanical circulatory support devices (left ventricular assist device, LVAD) as a bridge to heart transplantation (HTX) or destina- tion therapy for these critically ill patients [9]. With the widespread application of the continuous flow LVADs, 1-year survival is now $80 \%$, which is approaching that of heart transplantation at $86 \%[9,10]$. This matched case control study sought to evaluate the impact of LVAD and HTX on longterm outcome in the specific population

of patients with advanced structural heart disease after VT ablation.

\section{Methods}

\section{Study population}

Initially, a series of 309 consecutive patients that underwent catheter ablation of VT between 2012 and 2015 at the Heart Centre of Leipzig were included. The cohort consisted of 186 patients with ICM and 123 with non-ischemic cardiomyopathy (NICM). Patients with no structural heart disease (SHD) were excluded from the study. Classification took place after examining the patients with a combination of echocardiography, stress-test, coronary angiography, MRI or heart-biopsy. NICM was identified as an absence of relevant coronary artery disease and defined according to the criteria of the European Society of Cardiology Working Group on Myocardial and Pericardial Diseases. Chronic renal failure was present when the patient had a glomerular filter rate (GFR) of $<60 \mathrm{ml} / \mathrm{min} / 1.73 \mathrm{~m}^{2}$. All patients gave written informed consent for the procedure, as is in accordance with the institutional guidelines. The study was approved by the ethics committee. The decision on LVAD implantation or heart transplantation was based on clinical and haemodynamic data according to current guidelines. Whether the LVAD device was used as bridge to transplantation, bridge to decision or destination therapy was decided in the current HXT committee. After the initial cohort and their data were gathered, a matched case control study for the 21 patients receiving an LVAD, HTX or both was performed during follow-up. The patients were matched for age, gender, LVEF and LVEDV.

\section{Electrophysiological study and catheter ablation}

The methodology of the procedure has been described in detail elsewhere [11]. In brief, after deep sedation, femoral vein access was used to place one decapolar catheter in the coronary sinus and one quadripolar catheter in the right ventricular apex. A multichannel recording system (Prucka CardioLab; GE Healthcare, Wauke- 
Table 2 Univariate and multivariate analysis for predictors of mortality

\begin{tabular}{|c|c|c|c|c|}
\hline Variable & $\begin{array}{l}\text { No death } \\
(n=26)\end{array}$ & $\begin{array}{l}\text { Death } \\
(n=16)\end{array}$ & $\begin{array}{l}\text { Univariate analysis } \\
\text { ( } p \text {-value) }\end{array}$ & $\begin{array}{l}\text { Multivariate analy- } \\
\text { sis } \\
\text { ( } p \text {-value) }\end{array}$ \\
\hline $\begin{array}{l}\text { Male } \\
\text { Female }\end{array}$ & $\begin{array}{l}23(89 \%) \\
3(11 \%)\end{array}$ & $\begin{array}{l}15(94 \%) \\
1(6 \%)\end{array}$ & 0.571 & 0.775 \\
\hline Age (mean years) & $57 \pm 14$ & $60 \pm 8$ & 0.455 & 0.480 \\
\hline $\begin{array}{l}\text { ICM } \\
\text { NICM }\end{array}$ & $\begin{array}{l}19(73 \%) \\
7(27 \%)\end{array}$ & $\begin{array}{l}10(63 \%) \\
6(37 \%)\end{array}$ & 0.471 & 0.337 \\
\hline $\begin{array}{l}\text { NYHA I-II } \\
\text { NYHA III-IV }\end{array}$ & $\begin{array}{l}14(54 \%) \\
12(46 \%)\end{array}$ & $\begin{array}{l}10(63 \%) \\
6(38 \%)\end{array}$ & 0.582 & 0.763 \\
\hline Arterial hypertension & $20(77 \%)$ & $13(81 \%)$ & 0.740 & 0.953 \\
\hline Diabetes mellitus & $8(31 \%)$ & $9(56 \%)$ & 0.102 & 0.135 \\
\hline Renal failure & $15(58 \%)$ & $14(88 \%)$ & 0.042 & 0.071 \\
\hline LVEF (mean \%) & $30 \pm 8$ & $31 \pm 9$ & 0.818 & 0.584 \\
\hline LVEDV (mean ml) & $229 \pm 83$ & $242 \pm 100$ & 0.640 & 0.852 \\
\hline $\mathrm{AF}$ & $11(42 \%)$ & $11(69 \%)$ & 0.096 & 0.083 \\
\hline COPD & $5(19 \%)$ & $6(38 \%)$ & 0.191 & 0.060 \\
\hline AAD (baseline) & $17(65 \%)$ & $12(75 \%)$ & 0.276 & 0.593 \\
\hline AAD (follow-up) & $13(50 \%)$ & $10(63 \%)$ & 0.429 & 0.301 \\
\hline $\begin{array}{l}\text { ICD primary ind. } \\
\text { ICD secondary ind }\end{array}$ & $\begin{array}{l}20(77 \%) \\
4(15 \%)\end{array}$ & $\begin{array}{l}12(75 \%) \\
4(25 \%)\end{array}$ & 0.424 & 0.481 \\
\hline \multicolumn{3}{|l|}{ PAINESC Score } & \multirow[t]{3}{*}{0.879} & \multirow[t]{3}{*}{0.865} \\
\hline Low-intermediate & $12(46 \%)$ & $7(44 \%)$ & & \\
\hline High & $14(54 \%)$ & $9(56 \%)$ & & \\
\hline Electrical storm & $21(81 \%)$ & $12(75 \%)$ & 0.658 & 0.592 \\
\hline Epicardial VT ablation & $6(23 \%)$ & $5(31 \%)$ & 0.559 & 0.356 \\
\hline \multicolumn{3}{|l|}{$\mathrm{mmVT}$} & \multirow[t]{4}{*}{0.268} & \multirow[t]{4}{*}{0.192} \\
\hline $1-2$ & $12(46 \%)$ & $7(44 \%)$ & & \\
\hline $3-5$ & $12(46 \%)$ & $5(31 \%)$ & & \\
\hline$>5$ & $2(8 \%)$ & $4(25 \%)$ & & \\
\hline $\begin{array}{l}\text { Non-inducibility (end- } \\
\text { point) }\end{array}$ & $20(77 \%)$ & $13(81 \%)$ & 0.740 & 0.764 \\
\hline $\begin{array}{l}\text { Recurrence (re-do } \\
\text { ablation) }\end{array}$ & $15(58 \%)$ & $8(50 \%)$ & 0.627 & 0.716 \\
\hline \multicolumn{5}{|c|}{$\begin{array}{l}\text { SHD structural heart disease (ICM vs NICM), LVEF left ventricle ejection fraction, } L V E D V \text { left ventricle } \\
\text { end-diastolic LV volume, NYHA New York Heart Association, } A F \text { atrial fibrillation, } V T \text { ventricular tachy- } \\
\text { cardia, } A A D \text { antiarrhythmic drug, ICD implantable cardioverter/defibrillator, } m m V T \text { monomorphic } \\
\text { VT, RV right ventricle, PAINESD score: risk model for acute cardial decompensation during ablation } \\
\text { (pulmonary disease, age, ICM, NYHA, LV-EF }<25 \% \text {, VT-storm, diabetes mellitus type 2) }\end{array}$} \\
\hline
\end{tabular}

sha, WI, USA) was used for the signal's recording and ventricular stimulation to induce the VT. Fluoroscopy-guided transseptal puncture was used to access the left atrium (LA) and a long sheath (Agilis ${ }^{\circledR}$ Abbott Medical, St Paul, MN, USA) was introduced into the LA. When an epicardial approach was needed, an epicardial puncture and a long sheath (Agilis-EPI ${ }^{\circledR}$ Abbott Medical, St Paul, MN, USA) were used. Electroanatomic mapping was performed using the CARTO-3 system (Biosense Webster, Diamond Bar, CA, USA) or the EnSite-Velocity Navigation system (St. Jude Medical, St. Paul, MN, USA). Radiofre-
Follow-up

Follow-up included a review of records of all hospital and outpatient clinic visits and discussions with referring cardiologists and primary care physicians from the first ablation to the time of death/last visit or contact. If patients reported VT recurrence, additional examinations were provided. When indicated, the patients were treated with re-do procedures or additional antiarrhythmic drugs during follow-up. If the clinical status of the patients deteriorated, they were evaluated and listed for LVAD/HTX, according to the indications suggested by the existing guidelines. The patients with implanted LVAD or after HTX were routinely examined every 4-6 months in the authors' outpatient clinic. If the patient had an intracardiac defibrillator/pacemaker, routine device interrogation was also performed to detect asymptomatic arrhythmias.

\section{Statistical analysis}

Case control matching was performed according to patient age, gender, LVEF and LVEDV to create a database of matched patients with or without LVAD/HTX during follow-up using SPSS software (SPSS Inc., Chicago, IL, USA). Continuous variables were reported as mean \pm standard deviation and categorical variables as frequencies. Continuous variables were compared using the Student's $t$-test, while categorical variables were compared using the $X^{2}$ test. Univariate and multivariate analyses were performed in order to determine the predictive factors. Variables with a $P$-value of $\leq 0.2$ or important clinical or procedural variables in the univariate analysis were then included in the multivariate regression analysis for the determination of hazard ratio (HR) and its $95 \%$ confidence interval $(\mathrm{Cl})$. A $P$-value of $\leq 0.05$ was considered to be statistically significant. Survival rates were calculated and depicted with the Kaplan-Meier analysis. All analyses were performed using SPSS v24.0 (SPSS Inc., Chicago, IL, USA). 


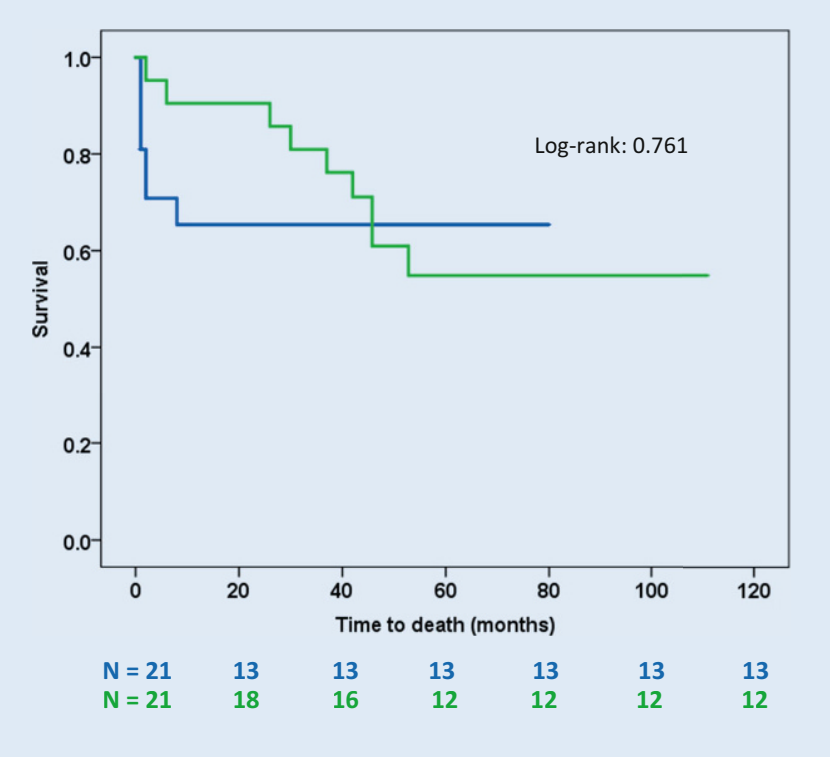

Fig. $1 \varangle$ KaplanMeier graph depicting survival of patients with left ventricular assist device/heart transplantation (green line) versus the control group (blue line, $N$ : number at risk; Log-rank: 0.761)

\section{Results}

Baseline patient characteristics, procedural data and outcome

- Table 1 shows the baseline patients characteristics, procedural data and long-term outcome. The mean follow-up duration was $44 \pm 33$ months. During this time, 15 patients underwent LVAD implantation and nine were transplanted. Three patients were implanted with an LVAD before eventually receiving an HTX. With the exception of more patients in the control group having chronic obstructive pulmonary disease (COPD) $(p=0.014)$, the other baseline characteristics, as well as the procedural data did not differ significantly between the two groups.

The incidence of major complications after ablation was similar in the two groups $(p=0.432)$. Five complications occurred in patients from the LVAD/HTX group; these consisted of one cardiac resuscitation during the procedure due to coronary air embolism, one gastrointestinal hemorrhage, one vascular access complication (pseudoaneurysm) needing surgical correction and one patient needing dialysis after the procedure. The three complications in the control group consisted of two patients with nosocomial pneumonia progressing to sepsis and one vascular access complication needing stenting.

Patients from the LVAD group suffered similar VT recurrence needing re-ablation procedures during follow-up when compared to the control group $(p=0.352)$.

In this matched cohort, 16 deaths occurred in the first 44 months after VT ablation: seven in the control group and nine in the LVAD/HTX group (• Table 2). All deaths in the LVAD/HTX group occurred in LVAD recipients, while all patients receiving $H T X$ survived follow-up. Three patients in the control group died of end-stage global heart failure, one after refractory VTs, two of sepsis and one death remained unclear. In the LVAD group, two patients died of right heart failure (one of them resulting from refractory VTs), two suffered lethal endocranial bleeding or stroke postoperatively, two died due to sepsis, one did not survive a postoperative acute abdomen, one died from an LVAD dysfunction and one death remained unclear. Evidently, the cause of death between the groups is different, with end-stage heart failure being the main lethal factor in the control group, whereas in the LVAD group right heart failure and device-associated complications (bleeding, infection, etc.) were the main causes of death.

\section{Predictors of mortality}

Using univariate testing, DM, chronic renal impairment, COPD and periprocedural complications were associated with higher mortality (- Table 2). Multivariate Cox regression survival analysis revealed that none of these parameters was an independent predictor of mortality.

While HTX patients all survived the follow-up, the LVAD recipients showed a similar survival to the control group (Log-rank: $0.761,0$ Fig. 1). The type of structural heart disease or the presence of recurrence did not differ in mortality rates in this patient cohort ( $p=0.715, p=0.325$, respectively). On the same note, a higher PAINESD score was not a predictor of mortality in the present cohort $(p=0.616)$.

\section{Discussion}

The principal findings in this analysis are the following: Patients with SHD and a history of VT ablation demonstrate similar survival after LVAD implantation when compared to the control group after 4 years. On the other hand, all patients receiving HTX had an excellent prognosis.

This study had a long follow-up of almost 4 years in a contemporary cohort of SHD patients and concentrates on the longterm outcome and possible benefit of LVAD and HTX for this specific challenging population. The existing studies all demonstrate a relatively poor longterm outcome after VT ablation. Muser et al. examined 282 NICM patients during a 4-year follow-up period, reporting transplant-free survival of $68 \%$ [2]. Kumar et al. reported a transplant-free survival of $74 \%$ in patients with NICM and $48 \%$ in patients with ICM after almost 6 years [3]. In their study, Frankel et al. [10] report $41 \%$ of patients reaching the primary endpoint of assist device/HTX or death after 1.2 years of follow-up. Accordingly, the present authors reported in their published study [11] a mortality rate of $31 \%$ with $5 \%$ of patients undergoing an LVAD implantation and $3 \%$ receiving $\mathrm{HTX}$, reaching to a combined endpoint of LVAD/HTX or death of $36 \%$ within the 4-year follow-up.

Clinical trials have shown clear survival benefits for LVAD implantation in endstage heart failure patients. The European Registry for Patients with Mechanical Circulatory Support (EUROMACS) recently reported a 1-year survival of $69 \%$ [12]. In their recent review, Miller et al. [13] report a mean post LVAD survival of 5 years. However, this comes with an increased complication rate. Infections, device thrombo- 
sis, bleeding, right heart failure and aortic valve failure are common problems that limit the prognosis of these patients [14].

In line with the existing literature, the LVAD patients in the present cohort died mostly of device-associated complications or right heart failure, with incessant VT being the cause of death in only one patient. These findings are in accordance with those of Galand et al. [15] and Efimova et al. [16], reporting that VT recurrence is not a predictor of mortality in these patients.

In a recent study [17], the MOMENTUM trial demonstrated the superiority of a fully magnetically levitated centrifugalflow pump, the HeartMate 3 (HM3 [Abbott Laboratories, IL, USA]) against an established axial-flow pump, the HeartMate II (HMII [Abbott Laboratories]), regarding severe complications such as stroke, pump thrombosis and severe bleeding. HeartMate 3 was not represented in this cohort and this could have an impact on the survival of LVAD patients. Whether the technological advances in LVAD devices can deliver better outcomes for SHD patients after VT ablation needs to be examined in larger randomised trials.

\section{Conclusions}

After performing case control matching in a contemporary cohort of patients with structural heart disease undergoing VT ablation, the patients after implantation of LVAD showed similar survival to the control group. Cause of death between the two groups differed, with device-associated complication and heart failure being the main cause of death in each group, respectively. The patients after heart transplantation had an excellent long-term outcome.

\section{Limitations}

There were several limitations in the present study. It is a retrospective, observational, single-centre analysis. The sample of patients is small and a possible benefit for LVAD could be statically underestimated. Enrolment for this study was undertaken $5-8$ years ago and the results are bound to the technology available at that time. This concerns not only the effectiveness and technology around VT ablation, but also the available LVAD devices. Recent studies on improved LVAD systems are reporting significantly fewer severe complications [16]. Similarly, the implantation criteria for the selection of patients, as well as the technological advances regarding LVAD implantation and HTX could have been a limitation during the study period. However, this allowed a long follow-up to determine outcome in these patients.

\section{Corresponding address}

\section{Angeliki Darma, MD}

Department of Electrophysiology, Heart Center University Leipzig

Struempellstraße 39, 04289 Leipzig, Germany

Angeliki.darma@helios-gesundheit.de

Funding. Open Access funding enabled and organized by Projekt DEAL.

\section{Declarations}

Conflict of interest. A.Darma, L. Bertagnolli, B. Dinov, A.S. Shamloo, F. Torri, E. Efimova, N. Dagres, D. HusserBollmann, A. Bollmann, G. Hindricks and A. Arya declare that they have no competing interests.

For this article no studies with human participants or animals were performed by any of the authors. All studies mentioned were in accordance with the ethical standards indicated in each case.

Open Access. This article is licensed under a Creative Commons Attribution 4.0 International License, which permits use, sharing, adaptation, distribution and reproduction in any medium or format, as long as you give appropriate credit to the original author(s) and the source, provide a link to the Creative Commons licence, and indicate if changes were made. The images or other third party material in this article are included in the article's Creative Commons licence, unless indicated otherwise in a credit line to the material. If material is not included in the article's Creative Commons licence and your intended use is not permitted by statutory regulation or exceeds the permitted use, you will need to obtain permission directly from the copyright holder. To view a copy of this licence, visit http://creativecommons.org/licenses/by/4.0/.

\section{References}

1. Muser D, Liang JJ, Castro SA, Lanera C, Enriquez A Kuo L, Magnani S, Birati EY, Lin D, Schaller R, Supple G, Zado E, Garcia FC, Nazarian S, Dixit S, Frankel DS, Callans DJ, Marchlinski FE, Santangeli P (2019) Performance of prognostic heart failure models in patients with nonischemic cardiomyopathy undergoing ventricular tachycardia ablation. JACC Clin Electrophysiol 5(7):801-813
2. MuserD, SantangeliP, CastroSA,PathakRK, Liang JJ, Hayashi T, Magnani S, Garcia FC, Hutchinson MD, Supple GG, Frankel DS, Riley MP, Lin D, Schaller RD, Dixit S, Zado ES, Callans DJ, Marchlinski FE (2016) Long-term outcome after catheter ablation of ventricular tachycardia in patients with nonischemic dilated cardiomyopathy. Circ Arrhythm Electrophysiol 9(10):e4328

3. Kumar S, Romero J, Mehta NK, Fujii A, Kapur S, Baldinger SH, Barbhaiya CR, Koplan BA, John RM, Epstein LM, Michaud GF, Tedrow UB, Stevenson WG (2016) Long-term outcomes after catheter ablation of ventricular tachycardia in patients with and without structural heart disease. Heart Rhythm 13(10):1957-1963

4. Santoro F, Metzner A, Scholz L, Brunetti ND, Heeger $\mathrm{CH}$, Rillig A, Reissmann B, Lemeš $C$, Maurer T, Fink T, Inaba O, Hashiguchi N, Kuck KH, Ouyang F, Mathew S (2019) Prognostic significance of ventricular tachycardia clustering after catheter ablation in non-ischemic dilated cardiomyopathy. Clin Res Cardiol 108(5):539-548

5. Schupp T, Akin I, Reiser L, Bollow A, Taton G, Reichelt $\mathrm{T}$, Ellguth $\mathrm{D}$, Engelke $\mathrm{N}$, Ansari $\mathrm{U}$, Mashayekhi K, Weiß C, Nienaber C, Akin M, Borggrefe M, Behnes M (2019) Prognostic impact of recurrences of ventricular tachyarrhythmias and appropriate ICD therapies in a high-risk ICD population. Clin Res Cardiol 108(8):878-891

6. Weidner K, Behnes M, Schupp T, Rusnak J, Reiser L, Taton G, Reichelt T, Ellguth D, Engelke N, Bollow A, El-Battrawy I, Ansari U, Hoppner J, Nienaber CA, Mashayekhi K, Weiß C, Akin M, Borggrefe M, Akin I (2019) Prognostic impact of chronic kidney disease and renal replacement therapy in ventricular tachyarrhythmias and aborted cardiac arrest. Clin Res Cardiol 108(6):669-682

7. Dinov B, FiedlerL,SchönbauerR, Bollmann A, RolfS, Piorkowski C, Hindricks G, Arya A (2014) Outcomes in catheter ablation of ventricular tachycardia in dilated nonischemic cardiomyopathy compared with ischemic cardiomyopathy: results from the Prospective Heart Centre of Leipzig VT (HELP-VT) study. Circulation 129(7):728-736

8. Santangeli P, Frankel DS, Tung R, Vaseghi M, Sauer WH, Tzou WS, Mathuria N, Nakahara $S$, Dickfeldt TM, Lakkireddy D, Bunch TJ, Di Biase L, Natale A, Tholakanahalli V, Tedrow UB, Kumar S, Stevenson WG, Bella DP, Shivkumar K, Marchlinski FE, Callans DJ (2017) International VT Ablation Center Collaborative Group. Early mortality after catheter ablation of ventricular tachycardia in patients with structural heart disease. J Am Coll Cardiol 69(17):2105-2115

9. Kirklin JK, Naftel DC, Pagani FD, Kormos RL, Stevenson LW, Blume ED, Myers SL, Miller MA, Baldwin JT, Young JB (2015) Seventh INTERMACS annual report: 15,000 patients and counting. JHeart Lung Transplant 34(12):1495-1504

10. Frankel DS, Liang JJ, Supple G, Dixit S, Hutchinson MD, Elafros MA, Callans DJ, Marchlinski FE (2015) Electrophysiological predictors of transplantation and left ventricular assist devicefree survival in patients with nonischemic cardiomyopathy undergoing ventricular tachycardia ablation. JACC Clin Electrophysiol 1 (5):398-407

11. Darma A, Bertagnolli L, Dinov B, Torri F, Shamloo AS, Lurz JA, Dagres N, Husser-Bollmann D, Bollmann A, Hindricks G, Arya A (2020) Predictors of long-term mortality after catheter ablation of ventricular tachycardia in a contemporary cohort of patients with structural heart disease. Europace 22(11):1672-1679 
12. de By TMMH, Mohacsi P, Gahl B, Zittermann A, Krabatsch T, Gustafsson F, Leprince P, Meyns B, Netuka I, Caliskan K, Castedo E, Musumeci F, Vincentelli A, Hetzer R, Gummert J, EUROMACS members (2018) The European Registry for Patients with Mechanical Circulatory Support (EUROMACS) of the European Association for Cardio-Thoracic Surgery (EACTS): second report. Eur J Cardiothorac Surg 53(2):309-316

13. Miller LW, Rogers JG (2018) Evolution of left ventricular assist device therapy for advanced heart failure: a review. JAMA Cardiol 3(7):650-658

14. Li X, Kondray V, Tavri S, Ruhparwar A, Azeze S, Dey A, Partovi S, Rengier F (2019) Role of imaging in diagnosis and management of left ventricular assist device complications. Int J Cardiovasc Imaging 35(7):1365-1377

15. Galand V, Flécher E, Auffret V, Boulé S, Vincentelli A, Dambrin C, Mondoly P, Sacher F, Nubret K, Kindo $M$, Cardi T, Gaudard $P$, Rouvière $P$, Michel $M$, Gourraud JB, Defaye P, Chavanon O, Verdonk C, Ghodbane W, Pelcé E, Gariboldi V, Pozzi M, Obadia JF, Litzler PY, Anselme F, Babatasi G, Belin A, Garnier F, Bielefeld M, Hamon D, Radu C, Pierre B, Bourguignon T, Eschalier R, D'Ostrevy N, Bories MC, Marijon E, Vanhuyse F, Blangy $H$, Verhoye JP, Leclercq C, Martins RP, ASSISTICD Investigators (2018) Predictors and clinical impact of late ventricular arrhythmias in patients with continuous-flow left ventricularassist devices. JACCClin Electrophysiol 4(9):1166-1175

16. Efimova E, Fischer J, Bertagnolli L, Dinov B, Kircher S, Rolf S, Sommer P, Bollmann A, Richter S, Meyer A, Garbade J, Hindricks G, Arya A (2017) Predictors of ventricular arrhythmia after left ventricular assist device implantation: a large single-center observational study. Heart Rhythm 14(12):1812-1819

17. Goldstein DJ, Naka Y, Horstmanshof D, Ravichandran AK, Schroder J, Ransom J, Itoh A, Uriel N, Cleveland JC Jr, Raval NY, Cogswell R, Suarez EE, Lowes BD, Kim G, Bonde P, Sheikh FH, Sood P, Farrar DJ, Mehra MR (2020) Association of clinical outcomes with left ventricular assist device use by bridge to transplant or destination therapy intent: the multicenter study of MagLev technology in patients undergoing mechanical circulatory support therapy with HeartMate 3 (MOMENTUM 3) randomized clinical trial. JAMA Cardiol 5(4):411-419

\section{Die Rolle der mechanischen Herzunterstützungssysteme und der Herztransplantation in der Langzeit Prognose von Patienten mit struktureller Herzerkrankung und stattgehabter VT Ablation}

Einführung: Die Ablation ventrikulärer Tachykardien (VT) bei Patienten mit struktureller Herzerkrankung wird mit fortgeschrittener Herzinsuffizienz und schlechter Überlebensprognose assoziiert.

Methoden und Ergebnisse: Diese gematchte Fall-Kontroll-Studie untersuchte den Einfluss einer linksventrikulären Assist-Device(LVAD)-Implantation und/oder einer Herztransplantation (HTX) auf die Überlebensprognose von Patienten mit struktureller Herzerkrankung und stattgehabter VT-Ablation. Von den initial 309 Patienten, die für eine VT-Ablation eingewiesen wurden (187 mit ischämischer Kardiomyopathie, mittleres Alter 64 \pm 12 Jahre, Ejektionsfraktion 34 $\pm 13 \%$ ), erhielten 15 ein LVAD und 9 eine HTX während des Follow-ups von $44 \pm 33$ Monaten. Die Langzeitüberlebensraten nach LVAD-Implantation waren ähnlich wie in der gematchten Kontrollgruppe $(p=0,761)$, aber die Todesursachen waren unterschiedlich. Alle Patienten nach HTX überlebten bis zum Ende des Follow-ups.

Schlussfolgerung: In unserer Studie zu Patienten mit struktureller Herzerkrankung und stattgehabter VT-Ablation zeigten die Patienten mit LVAD-Implantation nach 4 Jahren Follow-up ähnliche Überlebensraten wie die Kontrollgruppe, während Patienten mit HTX ein deutlich besseres Langzeitergebnis hatten.

\section{Schlüsselwörter}

Linksventrikuläres Assist-Device · Terminale Herzinsuffizienz · Ablation ventrikulärer Tachykardien . Langzeitergebnis · Mortalität 